\title{
ЛIТЕРАТУРОЗНАВСТВО
}

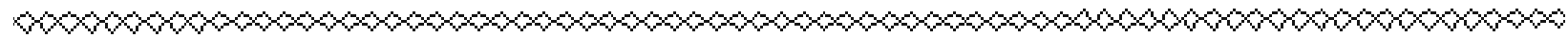

УДК 821.161.1Гоголь-23

https://doi.org/10.33989/2524-2490.2019.31.195629

\section{ДАЙСУКЭ АДАТИ}

(Cannopo) (Sapporo)

Place of work: Slavic-Eurasian Research Center

Country: Japan

Email: adaisuke@slav.hokudai.ac.jp

\section{ГОГОЯЬ И МЕДОДРАМА (К ПОСТАНОВКЕ ПРОБЛЕМЫ)}

Мета статті полягае в тому, щоб виявити прихований зв'язок між критичними поглядами М. Гоголя щзодо мелодрами та його поетикою. У праці порушується проблема, яка до сьогодні є малодослідженою в літературознавстві. У першій частині праці визначені дві провідні ознаки мелодрами, які найбільще не подобалися Гоголю. А в наступній частині розвідки показано співвідношення між рисами мелодрами, на які вказував митецьь, і поетикою шоку, щзо виявилася в різні періоди його творчості. Автор статті дійщов висновку, щзо негативні висловлювання Гоголя щзодо мелодрами походять від нестабільності взаємин між його поетикою $i$ мелодрамою. Новаторство Гоголя полягае в тому, щуо він виявив шок у контрасті незвичайного і звичайного. Згідно з уявленнями письменника, на сцені мелодрами ілюзорність життя тісно поєднуеться з хибним розумінням та використанням шоку. Критичний погляд мития на мелодраму sрунтується на подібній інтерпретацї мелодраматичного шоку: мелодрама створюе неповний $і$ недостатній, «хибний» шок. Справжній шок як контраст незвичайного і звичайного Гоголь шукав не у виняткових подіях мелодрами, а у буденному, щоб увиразнити мертвотність і аморальність життя.

Ключові слова: Гоголь; мелодрама; поетика; символ; шок; контраст між незвичайним і звичайним.

В статье, названной «Петербургские записки 1836 года», опубликованной в 1837 г. в журнале «Современник», Гоголь резко критикует мелодраму. По наблюдению автора статьи, «Петербург - большой охотник до театра», там видна сидьная дюбовь к театру. «И что же дается на наших театрах? - какие-нибудь мелодрамы и водевиди!.. Сердит я на мелодрамы и водевили» (Гоголь, 1952, т. VIII, с. 185-186).

«Уже лет пять, как медодрамы и водевиди завладели театрами всего света. Какое обезьянство! Даже немцы - ну кто бы мог подумать, что немцы, этот основательный, этот склонный к глубокому эстетическому наслаждению народ, немцы теперь играют и пишут водевиди, передедывают и клеят надутые и холодные мелодрамы! И пусть бы еще поветрие это занесено было могуществом мановения гения! Когда весь мир ладил под лиру Байрона, это не было смешно; в этом стремлении было даже что-то утешительное. Но Дюма, Дюканж и другие стади всемирными законодателями!.. Клянусь, XIX век будет стыдиться за эти пять лет» (Гоголь, 1952, т. VIII, с. 181-182). 
А лет десять спустя, в книге «Выбранные места из переписки с друзьями» (1847), Гоголь еще раз толкует о театре. Несмотря на сильные изменения, которые происходили в его мировоззрении в то время, отношение Гоголя к мелодраме осталось неизменным. Однако подобная настойчивость в негативной оценке медодрамы, на наш взгляд, дишь доказывает сильный и стабильный интерес Гоголя к данному предмету, напоминая нам нечто похожее на фрейдистскую концепцию «отрицания», то есть механизм защиты от угрозы чего-либо для «Я».

Цель данной статьи состоит в том, чтобы обнаружить скрытую связь между критическим взгдядом Гоголя на мелодраму и его общей поэтикой. Статья написана не для решения проблемы, а скорее для постановки проблемы, до сих пор оставшейся малоизученной в литературоведении. В первой части статьи мы укажем на два главных свойства мелодрамы, которые не нравидись Гоголю. В следующей части покажем соотношение между определенными Гоголем свойствами мелодрамы и поэтикой шока, проявившейся в разные периоды его творчества. В итоге мы обнаружим, что отрицательные высказывания Гоголя о мелодраме коренятся в нестабильности отношений между его поэтикой и мелодрамой.

В начале анализа мы посмотрим, почему мелодрама не нравится Гоголю. В вышеупомянутой его статье названы две причины подобного неблагоскионного отношения писателя к мелодраме. Во-первых, Гоголя задевает иностранное происхождение мелодрамы, ее «чужой» характер.

«На драматической сцене являлись мелодрама и водевидь, заезжие гости, которые были хозяевами во французском театре, а на русском играли чрезвычайно странную роль. Уже давно признано, что русские актеры несколько странны, когда представдяют маркизов, виконтов и баронов, как, вероятно, быди бы смешны французы, вздумав подделаться под русских мужиков; а сцены балов, вечеров и модных раутов, являющихся в русских пьесах - каковы они?» (Гогодь, 1952, т. VIII, с. 181).

Этот первый «порок» (по мнению Гоголя) мелодрамы сразу же, как считает писатель, неизбежно приведет ко второму - ложности ее представления. На сцене мелодрамы показывается не настоящая жизнь, а ложь, иллюзия: «Посмотрите, какое странное чудовище под видом мелодрамы забрадось между нас! Где же жизнь наша? где мы со всеми современными страстями и странностями? Хотя бы какоенибудь отражение ее видели мы в нашей мелодраме! Но лжет самым бессовестным образом наша мелодрама...» (Гоголь, 1952, т. VIII, с. 182).

«Если собрать все мелодрамы, какие были даны в наше время, то можно подумать, что это кунсткамера, в которую нарочно собраны уродливости и ошибки природы или, лучше, календарь, в котором записаны с календарною холодностию все странные происшествия, где против каждого числа выставдено: сегодня было в таком-то месте такое-то мошенничество; сегодня отрубили головы таким-то разбойникам и зажигателям; такой-то ремесленник заре́зал тогда-то жену свою... и тому подобное. Я воображаю, в каком странном недоумении будет потомок наш, вздумающий искать нашего общества в наших мелодрамах» (Гоголь, 1952, т. VIII, с. 183).

Таким образом Гоголь обнаруживает два главных недостатка мелодрамы - отчуждение от русской жизни и представление иддюзорной, ложной жизни. Эта характеристика мелодрамы в полной мере соответствовала жизни Петербурга, изображенной автором в первой части статьи. Сравнивая Москву с Петербургом, 
Гоголь писал: «Она еще до сих пор русская борода, а он уже аккуратный немец» (Гоголь, 1952, т. VIII, с. 177). «Москва кольнет Петербург тем, что он человек продажный и не умеет говорить по-русски. В Петербурге, на Невском проспекте, гуляют в два часа люди, как будто сошедшие с журнальных модных картинок, выставдяемых в окна, даже старухи с такими узенькими талиями, что делается смешно...» (Гоголь, 1952, т. VIII, с. 178).

В последней части статьи Гоголь подробно рассказывает о жизни в Петербурге, представляя ее как фантасмагорию. В данном описании видения Петербурга М. Ямпольский наблюдает обостренное ощущение симулятивности, «подменности» Петербурга, за которой нет оригинала. «Такого рода странный "негативный" город это радикальное отрицание референтности. Петербург - это картина, то есть репрезентация города, который не является Петербургом» (Ямподьский, 2007, с. 288). Подобная характеристика жизни Петербурга является особенностью фантастики Гоголя в период «Петербургских повестей» (Дотман, 1997). В данном контексте мелодрама, в понимании автора «Петербургских записок 1836 года», служит символом иллюзорности, не соответствуя настоящей жизни и обманывая людей.

Известно, что поэтика Гоголя имеет глубокое отношение к фантазии и фантасмагоричности жизни (Манн, 2007, с. 54-116). Заставить людей проснуться от илдюзии, которая по ошибке принимается за действительность, - это была одна из главных задач в поэтике Гоголя. В заметках к 1-й части «Мертвых душ» Гогодь записывает: «Как пустота и бессидьная праздность жизни сменяется мутною, ничего не говорящею смертью. Как это страшное событие совершается бессмысленно. Не трогающая<?>. Смерть поражает нетрогающ<ийся?> мир. - Еще сильнее между тем должна предста<виться?> читателю мертвая бесчувственность жизни» (Гоголь, 2012, т. 7, кн. 1, с. 757).

Отсюда мотив эстетического и этического пробуждения, мотив шока в поэтике Гоголя, самым известным примером которого служит, конечно, поэтика «окаменения» в «немой сцене» «Ревизора» (Манн, 1966, 1971, 1987, 1989, 2007). Почти в то же время, когда Гоголь писал «Петербургские записки 1836 года», в одной статье из сборника «Арабески» (1835) он подробно объяснял поэтику шока. Выражая свое предпочтение готической архитектуре по сравнению с другими видами архитектуры, автор статьи рекомендует исподьзовать высокую архитектуру тодько в церквях. «Весьма не мешает вспомнить великую старую истину, что народ не в силах понять религии в такой же самой чистоте и бестелесности, как получившие высшее образование, что на него более всего производят впечатление видимые предметы; что чем меньше этот видимый предмет на него действует, тем слабее его энтузиазм и простая вера. Великолепие повергает простолюдина в какое-то онемение, и оно-то единственная пружина, двигающая диким человеком. Необыкновенное поражает всякого, но тогда только, когда оно смело, резко и разом бросается в глаза» (Гоголь, 2009, т. 3, с. 105).

Значит, шок, физическое и нравственное потрясение является кдючевым приемом в поэтике Гогодя. Однако мы можем подозревать, что подобный эффект шока найдется именно в центре поэтики мелодрамы, которую современный американский литературный критик Питер Брукс в своей одноименной книге назвал «мелодраматическим воображением» (Peter Brooks, 1995). По Бруксу, сила мелодрамы состоит в необыкновенной эмоции, которая во время представления пьесы передается зрителям в схеме сильного контраста добра и зла и окончательной победы первого. 
Между тем, в тридцатых годах мелодрама на русской сцене специально выделила шок и подчеркнула его для сценического эффекта и зрелищности. Современная исследовательница А. Самохина указала на качественные и «количественные» изменения, которые мелодрама на русской сцене претерпевала с конца 1820-х гг. В критике мелодраму все чаще стали называть «кровавой» (Самохина, 2015, с. 133). «Театральные знатоки и любители сетуют на "новую методу" современных драм, где с первых же сцен, едва открывается занавес, зрителя погружают в водоворот ужасов, страхов и страстей» (Самохина, 2015, с. 134).

Гоголь сам пленился поэтикой «неистовой» школы французской литературы, что ясно из его отрывка «Кровавый бандурист (глава из романа)». В. В. Виноградов тщательно следил за развитием «неистовой» поэтики и ее переходом в поэтику «натуральной» школы, что нашло отражение в творчестве писателя. Приведя имена Виктора Гюго, Жюля Жанена, Эжена Сю, Оноре де Бальзака, Александра Дюма, Виноградов пишет: «"Кошмарный жанр" юной Франции с конца 20-х годов XIX столетия волнует русское читающее общество, вызывая протесты и подражания» (Виноградов, 1976, с. 80).

В данном культурном контексте мы можем предполагать, что Гоголь так резко и упорно критиковал мелодраму именно потому, что сознавал близость его поэтики шока и эмоционального эффекта, создаваемого медодрамой. Об этом свидетельствует его более позднее высказывание о мелодраме. В статье из «Выбранных мест из переписки с друзьями», говоря своему адресату о пользе театра, Гоголь требует строго раздичать два типа театра: «Театр и театр - две разные вещи, равно как и восторг самой публики бывает двух родов» (Гоголь, 1952, т. VIII, с. 277).

«Отделите только собственно называемый высший театр от всяких балетных скаканий, водевилей, мелодрам и тех мишурно-великолепных зрелищ для глаз, угождающих разврату вкуса или разврату сердца, и тогда посмотрите на театр. Театр, на котором представляются высокая трагедия и комедии, должен быть в совершенной независимости от всего. Странно и соединить Шекспира с плясуньями или с плясунами в лайковых штанах. Что за сближение? Ноги - ногами, а голова - головой» (Гоголь, 1952, т. VIII, с. 268).

Характерно, что при описании необыкновенного сюжета, предпочитаемого современной ему мелодрамой в «Петербургских записках 1836 года», автор статьи не использует слов, связанных с семантикой ужаса и страха. Вопреки общему представлению современной ему критики, Гоголь считал, что мелодрама не может возбудить такой сильный шок, как ужас и страх.

«Странное сделалось сюжетом нынешней драмы. Всё дело в том, чтобы рассказать какое-нибудь происшествие, непременно новое, непременно странное, дотоле неслыханное и невиданное: убийство, пожары, самые дикие страсти, которых нет и в помине в теперешних обществах! Как будто в наши европейские фраки переоделися сыны палящей Африки. Палачи, яды - эффект, вечный эффект, и ни одно лицо не возбуждает никакого участия! Никогда еще не выходил из театра зритель расстроенный, в слезах; напротив того, в каком-то тревожном состоянии торопливо садился он в карету и долго не мог собрать и сообразить своих мыслей. И среди нашего утонченного, образованного общества такой род зрелища!» (Гоголь, 1952, т. VIII, с. 182). 
Достаточно сильный, настоящий шок должно искать, по мнению писателя, не в новом, странном, неслыханном и невиданном, то есть не в искдючениях, из которых состоят сцены мелодрамы. Он найдется в самом обыкновенном. «Непостижимое явление: то, что вседневно окружает нас, что неразлучно с нами, что обыкновенно, то может замечать один только глубокий, великий, необыкновенный талант. Но то, что случается редко, что составдяет исключения, что останавдивает нас своим безобразием, нестройностию среди стройности, за то схватывается обеими руками посредственность. И вот жизнь глубокого таланта течет во всем своем раздиве, со всею стройностью, чистая как зеркало, отражая с одинаковою ясностию и темные и светдые облака: у посредственности она влечется мутною и грязною волною, не отражая ни ясного, ни темного» (Гоголь, 1952, т. VIII, с. 182).

Подобные взгляды можно найти и в статье «Нескодько слов о Пушкине», вкдюченной в «Арабески», в которой Гоголь освещает развитие творчества Пушкина и высоко оценивает его последние сочинения, принятые публикой «как доказательство совершенного падения таланта» (слова Б. Белинского по поводу восприятия «Бориса Годунова» (Белинский, 1955, с. 505). Гоголь объясняет реакцию публики «естественной причиной»: «<...> то, что мы реже видим, всегда сильнее поражает наше воображение, и предпочесть необыкновенному обыкновенное есть больше ничего кроме нерасчет поэта, нерасчет перед его многочисленною публикою, а не перед собою» (Гоголь, 2009, т. 3, с. 94). Как отмечает В. В. Виноградов, Гогодь здесь раскрывает «основной принцип своей художественной стидистики» (Виноградов, 2003, с. 76) и издагает, что «чем предмет обыкновеннее, тем выше нужно быть поэту, чтобы извлечь из него необыкновенное и чтобы это необыкновенное было между прочим совершенная истина» (Гоголь, 2009, т. 3, с. 94).

Исходя из мелодраматической поэтики ужаса и страха, Гогодь избегает ее односторонности: шок не исключительно в необыкновенном или в обыкновенном. Существенно преобразовано общепринятое представление о шоке, по которому шок производится непременно из мелодраматического необыкновенного. Новизна Гоголя состоит в том, что он обнаружия шок в самом контрасте необыкновенного и обыкновенного.

В результате нашего анадиза оказалось, что, по представлению Гоголя, на сцене мелодрамы илдюзорность жизни тесно сочетается с ложным пониманием и использованием шока. Критический взгляд писателя на мелодраму глубоко основан на подобной интерпретации мелодраматического шока: мелодрама дает неполный и недостаточный, так сказать, «дожный» шок. Настоящий шок как контраст необыкновенного и обыкновенного должно искать не в искдючительных событиях мелодрамы, но в обыкновенном, чтобы еще сильнее «доджна представиться читателю мертвая бесчувственность жизни».

\section{СПИСОК ИСПОЯЬЗОВАННЫХ ИСТОЧНИКОВ}

Белинский В. Полное собрание сочинений : в 13 т. Москва, 1955. Т. 7.

Виноградов В. Романтический натурализм (Жюль Жанен и Гоголь). Виноградов В. В. Поэтика русской литературы : избранные труды. Москва, 1976. С. 76-100.

Виноградов В. Язык Гоголя и его значение в истории русского языка. Виноградов В. В. Избранные труды. Язык и стиль русских писателей. От Гоголя до Ахматовой. Москва, 2003. С. 54-96.

Гоголь Н. Полное собрание сочинений : в 14 т. Москва ; Ленинград : АН СССР, 1937-1952.

Гоголь Н. Полное собрание сочинений и писем : в 23 т. Москва : ИМЛИ РАН. 2003-2012.

Лотман Ю. Художественное пространство в прозе Гоголя. Лотман Ю. М. О русской литературе. СанктПетербург, 1997. С. 251-293. 
Манн Ю. Формула онемения у Гоголя. Известия АН СССР: Серия литературы и языка. 1971. Т. 30, вып. 1. С. 28-36.

Манн Ю. «Скульптурный миф» Пушкина и гоголевская формула окаменения. Пущкинские чтения 8 Тарту. Талдин, 1987. С. 18-21.

Манн Ю. «Ужас оковал всех...» (О немой сцене в «Ревизора» Гоголя). Вопросы литературы. 1989. № 8. C. 223-235.

Манн Ю. Комедия Гоголя «Ревизор». Москва, 1966.

Манн Ю. Творчество Гоголя: Смислл и Форма. Санкт-Петербург, 2007.

Самохина А. «Соперница гордой Мельпомены». Мелодрама в русской театральной критике тридцатых - сороковых годов XIX века. (Ч. ІІ). Вестник Академии Русского балета им. А. Я. Вагановой. 2015. № 1. С. 133-147.

Ямпольский М. Ткач и визионер: Очерки истории репрезентации, или о материальном и идеальном в культуре. Москва : Наука. 2007.

Brooks Peter. The Melodramatic Imagination: Balzac, Henry James, Melodrama, and the Mode of Excess. New Haven : Yale University Press. 1995.

\section{DAISUKE ADACHI}

\section{GOGOL AND MELODRAMA (TO THE PROBLEM SETTINGS)}

The aim of this article is to indicate a connection between Gogol's critical remarks on melodrama and his poetics, a problem that has not been studied sufficiently. In the first part of the article, we point two negative characters that Gogol reveals in the melodrama - its alienation from Russian life and presentation of an illusory one. Melodrama serves as a symbol of illusion that does not correspond to real life and deceives people. Shattering the illusory vision mistaken for reality is one of the main tasks of Gogol's poetics, which requires physical and moral shock as a key device for aesthetic and ethical awakening. However, as we see in the second part of the article, a shock is found in the center of melodrama's poetics, especially in the context of the 1830s Russian theater and literature that exaggerated such strong emotions as horror and fear. We can suspect that Gogol's harsh and chronic criticism of melodrama has its roots in the similarity between his poetics of shock and the emotional effect created by melodrama. In the final part, we see Gogol's transformation of a generally accepted understanding that shock is produced exclusively by the melodramatic extraordinary. According to Gogol, melodrama demonstrates a false understanding and use of shock to create the illusory vision of life on the stage. Gogol's novelty lies in his redefining the shock as a contrast between the extraordinary and the ordinary (and not as the extraordinary itself). A real shock, Gogol insists, extracted not from the exceptional events in melodrama but from the representation of ordinary life, makes a contrast in ordinary life and shatters the reader's illusory vision of life.

Key words: Gogol; melodrama; poetics; symbol; shock; contrast between the extraordinary and the ordinary.

\section{REFERENCES}

Belinskii, V. (1955). Polnoe sobranie sochinenii [Full collected works] (Vol. 7). Moskva [in Russian].

Brooks, P. (1995). The Melodramatic Imagination: Balzac, Henry James, Melodrama, and the Mode of Excess. New Haven: Yale University Press.

Gogol, N. (1937-1952). Polnoe sobranie sochinenii [Full collected works] (Vol. 1-14). Moskva; Leningrad [in Russian]. Gogol, N. (2003-2012). Polnoe sobranie sochinenii I pisem [Full collected works and letters] (Vol. 1-23). Moskva: IMLI RAS [in Russian].

Iampolskii, M. (2007). Tkach i vizioner: Ocherki istorii reprezentatcii, ili o materialnom i idealnom v kulture. [Weaver and Visionary: Essays on the History of Representation, or on the Material and Ideal in Culture]. Moskva: Nauka [in Russian].

Lotman, Iu. (1997). Khudozhestvennoe prostranstvo v proze Gogolia [Art space in Gogol's prose]. In Lotman Iu. M. O russkoi literature [About Russian literature] (pp. 251-293). Sankt-Peterburg [in Russian].

Mann, Iu. (1971). Formula onemeniia u Gogolia [Gogol's formula for numbness]. Izvestiia AN SSSR: Seriia literatury i iazyka [Izvestiya AN SSSR: A series of literature and language], 30, 1, 28-36 [in Russian].

Mann, Iu. (1987). «Skulpturnyi mif» Pushkina i gogolevskaia formula okameneniia ["Sculptural myth" of Pushkin and the Gogol's petrification formula]. In Pushkinskie chteniia v Tartu [Pushkin Readings in Tartu] (pp. 18-21). Tallin [in Russian].

Mann, Iu. (1989). «Uzhas okoval vsekh...» (Onemoi stcene v «Revizora» Gogolia) [“Horror fettered everyone ...” (About the silent scene in "The Examiner" by Gogol)]. Voprosy literatury [Literature Issues], 8, 223-235 [in Russian].

Mann, Iu. (1966). Komediia Gogolia «Revizor» [Gogol's comedy The Examiner]. Moskva [in Russian] 
Mann, Iu. (2007). Tvorchestvo Gogolia: Smysl i Forma [Gogol's Creativity: Meaning and Form]. Sankt-Peterburg [in Russian].

Samokhina, A. (2015). «Sopernitca gordoi Melpomeny». Melodrama v russkoi teatralnoi kritike tridtcatykh - sorokovykh godov XIX veka. (Ch. II) ["The rival of the proud Melpomene." Melodrama in Russian theater criticism of the thirties and forties of the 19th century. (Part II)]. Vestnik Akademii Russkogo baleta im. A. Ia. Vaganovoi [Bulletin of the Academy of Russian Ballet. AND I. Vaganova], 1, 133-147 [in Russian].

Vinogradov, V. (1976). Romanticheskii naturalizm (Zhiul Zhanen i Gogol) [Romantic Naturalism (Jules Janin and Gogol)]. In Vinogradov V. V. Poetika russkoi literatury: Izbrannye trudy [The Poetics of Russian Literature: Selected Works] (pp. 76-100). Moskva [in Russian].

Vinogradov, V. (2003). Iazyk Gogolia i ego znachenie v istorii russkogo iazyka [Gogol's language and its significance in the history of the Russian language]. In Vinogradov V. V. Izbrannye trudy. Iazyk $i$ stil russkikh pisatelei. Ot Gogolia do Akhmatovoi [Selected Works. Language and style of Russian writers. From Gogol to Akhmatova] (pp. 54-96). Moskva [in Russian].

Отримано 1.04.2019 p. 